\title{
Modellers claim wars are predictable
}

\author{
Insurgent attacks follow a universal pattern of timing and casualties.
}

Seemingly random attacks and a shadowy, mysterious enemy are the hallmarks of insurgent wars, such as those being fought in Afghanistan and Iraq. Many social scientists, as well as the military, hold that, like conventional civil wars, these conflicts can't be understood without considering local factors such as geography and politics. But a mathematical model published today in Nature (see page 911) suggests that insurgencies have a common underlying pattern that may allow the timing of attacks and the number of casualties to be predicted.

"We found that the way in which humans do insurgent wars - that is, the number of casualties and the timing of events - is universal," says team leader Neil Johnson, a physicist at the University of Miami in Florida. "This changes the way we think insurgency works."

Johnson and his colleagues argue that the pattern arises because insurgent wars lack a coherent command network and operate more as a "soup of groups", in which cells form and disband when they sense danger, then reform in different sizes and composition. The timing of attacks, the authors say, is driven by competition between insurgent groups for media attention.

Johnson, who has presented preliminary versions of the work to the US military, says that the findings allow a glimpse into the heart of insurgency behaviour. "We can get a sense of what is going on and what might happen if we intervened in certain ways," he says. He is now working to predict how the insurgency in Afghanistan might respond to the influx of foreign troops recently announced by US President Barack Obama.

\section{Power law}

The researchers collected data on the timing of attacks and number of casualties from more than 54,000 events across nine insurgent wars, including those fought in Iraq between 2003 and 2008 and in Sierra Leone between 1994 and 2003. By plotting the distribution of the frequency and size of events, the team found that insurgent wars follow an approximate power law, in which the frequency of attacks decreases with increasing attack size to the power of 2.5. That means that for any insurgent war, an attack with 10 casualties is 316 times more likely to occur than one with 100 casualties (316 is 10 to the power of 2.5).

"This is surprising because these wars are all fought in different terrains and under different circumstances," says Johnson. "It shows that

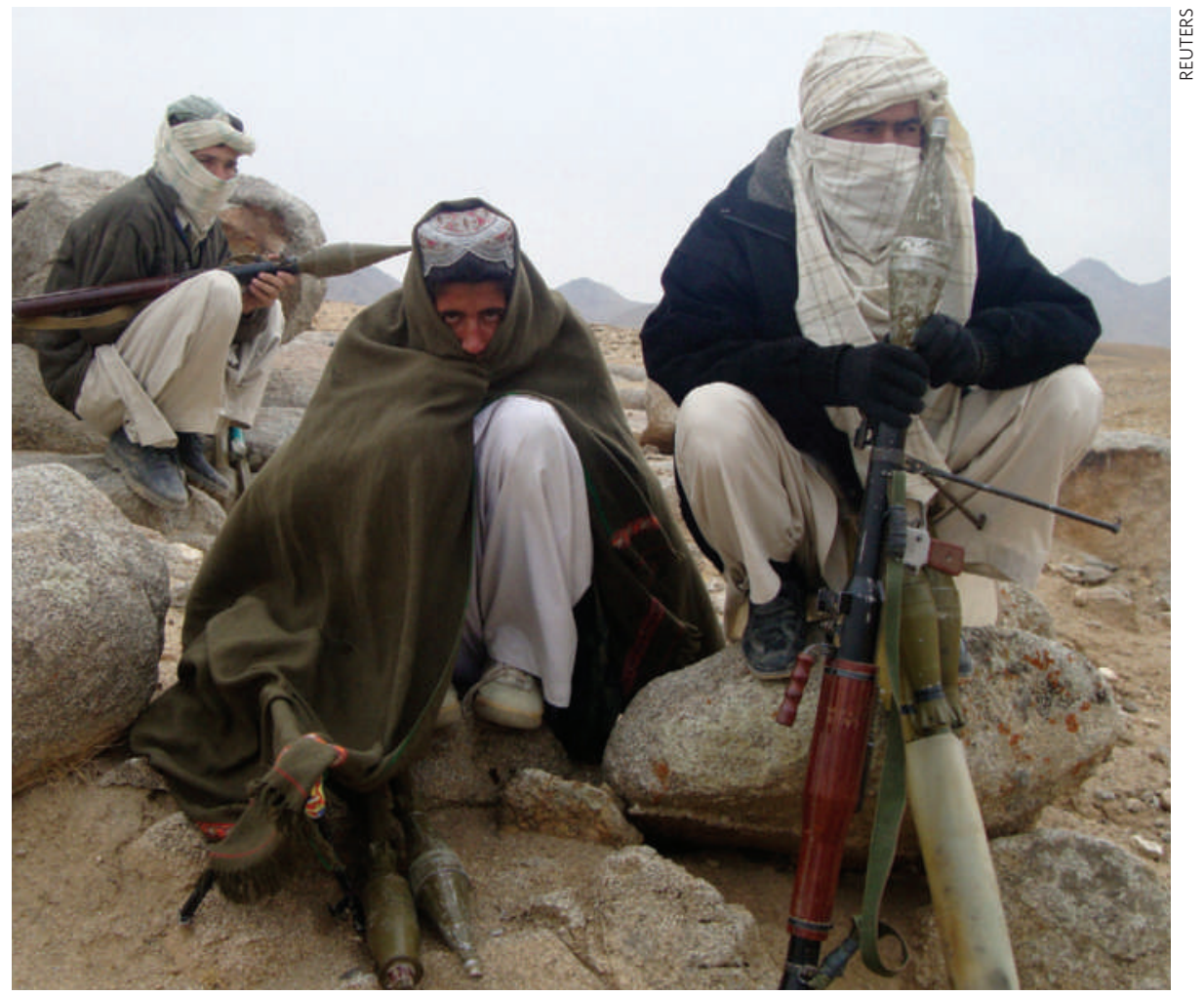

Could a model help to predict the number of casualties in conflicts such as that in Afghanistan?

there is something going on in the way these wars are fought that is common to all."

To explain what was driving this common pattern, the researchers created a mathematical model that assumes that insurgent groups form and fragment when they sense danger, and strike in well-timed bursts to maximize their media exposure. The model gave results that resembled the power-law distribution of actual attacks.

"They show a nice agreement between the data and their model, which is an important first step," says Aaron Clauset, who researches the mathematics of conflict at the Santa Fe Institute in New Mexico. But he and others question the model's assumptions, such as the number of insurgents in the conflict remaining roughly fixed over time. Clauset says that this idea does not match with other findings.

The model also assumes that insurgent groups can freely break up then re-form. But Roy Lindelauf, who models terrorist networks at the Netherlands Defence Academy in Breda, notes that some insurgents in Iraq are battling each other as well as the coalition forces, and would therefore not merge into a single group.

Lars-Erik Cederman, a researcher in international conflict at the Swiss Federal Institute of Technology in Zurich, adds that the model "has the potential to improve knowledge about warfare". But, he says, the authors "go too far in claiming they have found a universal underlying pattern" because their work includes only nine wars. Cederman, part of a group that regards insurgency as similar to general warfare, also says that although terrorist attacks can be driven by competition for media attention, it remains far from clear whether insurgencies have the same motive.

"In human social systems, it is usually difficult to nail down what mechanism is behind an observed behavioural pattern," Clauset says. "There are almost always several equally plausible explanations that need to be considered."

Johnson agrees that there could be other explanations for the pattern his group has found. But he says, "We have looked for many years for a model, and this is the only one we have found that explains the data."

Natasha Gilbert 